Jurnal Indonesia Sosial Teknologi:p-ISSN: 2723 - 6609

e-ISSN :2745-5254

Vol. 2, No.12 Desember 2021

\title{
PERANCANGAN SISTEM PENJUALAN PAKAIAN BERBASIS WEB DI PT.QUADRAN ENERGI REKAYASA MENGGUNAKAN CODEIGNITER3
}

\author{
Resi Alpiana ${ }^{1}$, Widantia Mustika ${ }^{2}$, Rini Tisnawati ${ }^{3}$ \\ Program Studi Manajemen Informatika, Politeknik Piksi Ganesha Bandung 1,2,3 \\ Email: ralpiana@piksi.ac.id¹ wmustika@piksi.ac.id² rinitisnawati09@gmail.com³
}

\begin{abstract}
Abstrak
Tujuan penulis melakukan penelitian ini adalah untuk melakukan analisis dan perancangan sistem informasi penjualan di PT.Quadran Energi Rekayasa. Metode pengembangan perangkat lunak yang penulis gunakan adalah metode kualitatif dengan teknik pengumpulan data dengan melakukan studi pustaka,observasi, dan juga wawancara. Dari penelitian yang telah dilakukan, diketahui bahwa sistem penjualan yang digunakan masih sistem lama dan lambat dalam hal penginputan pengelolaan data dan laporan.Sehingga dibuatlah sistem yang baru. Oleh karna itu dibutlah perancangan sistem informasi penjualan menggunak bahasa pemograman PHP dan framework codeignite3 dengan database My SQL. Dengan adanya sistem penjualan ini diharapkan menjadi solusi dari permasalahan yang dihadapi, agar penjualan bisa lebih efektif dan efisien.
\end{abstract}

Kata kunci: sistem informasi; penjualan; Framework Codeigniter; Mysql

\section{Abstract}

The author's purpose of doing this research is to analyze and design a sales information system at PT.Quadran Energi Rekayasa. The software development method that the author uses is a qualitative method with data collection techniques by conducting literature studies, observations, and also interviews. From the research that has been done, it is known that the sales system used is still an old system and is slow in terms of inputting data management and reports. So a new system was created. Therefore, it is necessary to design a sales information system using the PHP programming language and the Codeignite 3 framework with MY SQL database. With this sales system, it is expected to be a solution to the problems faced, so that sales can be more effective and efficient.

Keywords: information system;, selling; Framework Codeigniter; Mysql

\section{Pendahuluan}

Kemajuan teknologi yang sangat pesat ini menuntut banyak perusahaan untuk mengikuti perkembangan teknologi apalagi perusahaan yang bergerak di bidang penjualan.

Penjualan adalah aktivitas dalam menjual produk atau jasa. Aktivitas penjualan ini merupakan sebuah hal yang sangat penting bagi sebuah perusahaan, terutama untuk meraih keuntungan. 
Dulu sebelum internet menybar luas biasanya para penjual menawarkan barang pandemi saat ini banyak toko terkena dampak. permasalahan yang dihadapi sekarang adalah bagaimana cara penjual bisa menjual berbagai produknya dengan cara mudah dan dapat diakses oleh masyarakat luas dalam kondisi sekarang ini.

Maka tujuan web ini dibuat agar penjual dapat memberikan layanan informasi produk yang ditawarkan secara jelas dan mudah, bisa memberi informasi berupa detail bahan, warna, ukuran dan harga (Aryani, 2020). dengan cara memberi informasi berupa detail barang, bahan, ukuran, dan warna. Dengan begitu masyarakat akan lebih mudah untuk berbelanja dan mengetahu detail barang yang mereka inginkan.

Oleh karena itu pada kesempatan ini penulis merasa tertatik dan melaksanakan Praktek Kerja Lapangan di PT. QER ini karena ingin mengetahui bagaimana cara membuat aplikasi transaksi penjualan berbasis web dengan menggunakan bahasa pemograman PHP framework Codeigniter dan Database Mysql (Pasaribu \& Taryanto, 2018).

Menurut (Furqon, 2013), "sistem informasi penjualan merupakan suatu sistem yang berfungsi untuk mengolah data-data terkait dengan kegiatan penjualan baik dari transaksi pembelian sampai transaksi penjualan digunakan untuk mendukung kegiatan penjualan tersebut." Dapat disimpulkan bahwa sistem informasi penjualan dapat memudahkan pengolahan data baik itu dari trasnsaksi penjualan maupun pembelian.

Menurut (Basu, 2008) penjualan adalah ilmu dan seni mempengaruhi pribadi yang dilakukan oleh penjual untuk mengajak orang lain agar bersedia membeli barang yang ditawarkan. Dapat disimpulkan bahwa Penjualan adalah aktivitas menawarkan barang atau jasa kepada konsumen agar konsumen tertarik membeli produk atau jasa yang kita tawarkan (Lestari, 2016).

Menurut (Rerung, 2018) mendefinisikan bahwa "web adalah jaringan komputer yang terdiri dari kumpulan situs internet yang menawarkan teks dan grafik dan suara dan sumber daya animasi melalui hypertext transfer protocol”. Web sering disebut juga dengan website, situs, site yang merupakan kumpulan dari halaman web (web page) yang menjadi bagian dari sebuah nama domain atau sub domain di World Wide Web (WWW) di internet. Halaman web yang diakses publik dan tampil dimonitor merupakan halama induk (home page) dan sering diterjemahkan sebagai beranda/ halaman muka.

\section{Metode Penelitian}

Dalam perancangan aplikasi yang dibuat, metode yang digunakan oleh penulis menggunakan metode kualitatif dan deskriptif diperoleh berdasarkan hasil wawancara dengan user, meganalisis sistem yang dibutuhkan, dan melakukan Teknik pengumpulan data dengan cara observasi, wawancara, dan studi pustaka guna mendapatkan referensi yang berkaitan dengan perancangan yang akan dilakukan.

Metode kualitatif menurut ( $\underline{\text { Sugiyono, }}$ 2018) metode penelitian kualitatif adalah metode penelitian yang berlandaskan pada filsafat postpositivisme, digunakan untuk meneliti pada kondisi obyek yang alamiah, (sebagai lawannya adalah eksperimen) 
dimana peneliti adalah sebagai instrument kunci, teknik pengumpulan data dilakukan secara trianggulasi (gabungan), analisis data bersifat induktif/ kualitatif, dan hasil penelitian kualitatif lebih menekankan makna dari generalisasi.

Sedangkan metode deskriptif Menurut (Nazir, 2011) metode deskriptif adalah suatu metode dalam meneliti status sekelompok manusia, suatu objek, suatu kondisi, suatu sistem pemikiran, ataupun suatu kelas peristiwa pada masa sekarang. Tujuan dari penelitian deskriptif ini adalah untuk membuat deskripsi, gambaran atau lukisan secara sistematis, faktual dan akurat mengenai fakta-fakta, sifat-sifat serta hubungan antar fenomena yang terselidiki (Nazir, 2011).

Pada perancangan aplikasi, penelitian ini menggunakan bahasa pemrograman PHP serta mengimplementasikan framework Codeigniter3 untuk optimalisasi tampilan. Spesifikasi hardware yang digunakan adalah menggunakan Intel Celeron, Operating System Windows 10, RAM 4GB (Daqiqil, 2011).

Pada penelitian ini untuk perancangan aplikasi yang telah direncanakan, digunakan model pengembangan sistem prototype seperti pada gambar 1, dan adapun tahapannya sebagai berikut.

\section{a. Communication}

Metode prototipe dimulai dari tahap komunikasi. Tim pengembang perangkat lunak melakukan wawancara melalui pertemuan dengan para stakeholder untuk menentukan kebutuhan perangkat lunak yang saat itu diketahui dan untuk menggambarkan area-area dimana definisi lebih jauh untuk literasi selanjutnya. Pada tahap ini, penulis menerima informasi jenis usaha konsumen yang datang ke PT.QER yaitu menjual pakaian (Salahudin \& Rosa, 2013).

\section{b. Quick Plan:}

Perencanaan literasi dalam pembuatan prototype dilakukan secara cepat. Setelah itu dilakukan pemodelan dalam bentuk "rancangan cepat". Ditahap ini, penulis berdasarkan informasi yang diterima, sejauh mana ruang lingkup dari aplikasi yang dibutuhkan. Selain itu juga dilakukan pencarian referensi yang berhubungan dengan penelitian yang sedang dilakukan.

\section{c. Modeling}

Pembuatan rancangan cepat berdasarkan pada representasi aspek-aspek perangkat lunak yang akan terlihat oleh para end user (misalnya rancangan antarmuka pengguna atau format tampilan). Pada tahap ini, penulis menggunakan Analisa kebutuhan software, Desain.

\section{d. Construction}

Rancangan cepat merupakan dasar untuk memulai konstruksi pembuatan prototype.

\section{e. Deployment Delivery Feedback:}

Prototype lalu diserahkan kepada para pegambil keputusan untuk mengevaluasi prototype yang telah dibuat sebelumnya dan memberikan umpan balik yang akan digunakan untuk memperbaiki spesifikasi kebutuhan. Iiterasi terjadi saat pengembang melakukan perbaikan terhadap prototype tersebut. 
Resi Alpiana, Widantia Mustika, Rini Tisnawati.

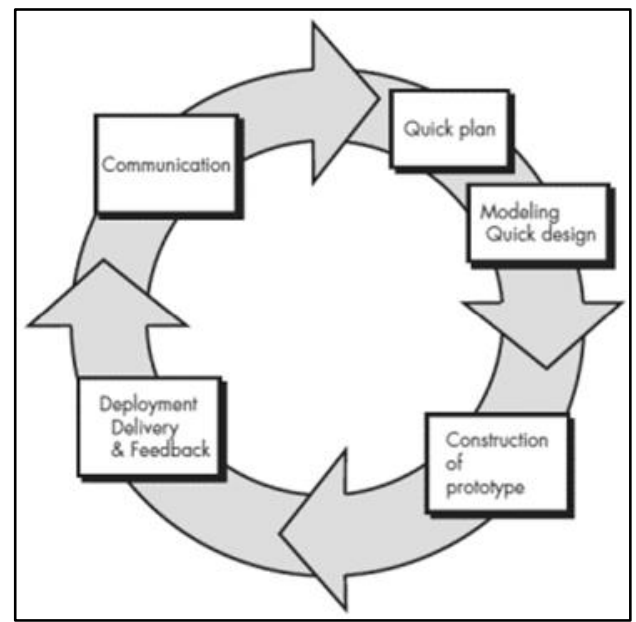

Gambar.1 Prototype model yang diusulkan.

Gambar 1 menunjukan sebuah model yang diusulkan pada penelitian yang dilakukan untuk pengembangan sistem

\section{Hasil dan Pembahasan}

\section{Perancangan Sistem}

\section{a. Usecase Diagram}

Menurut istilah, use case adalah sebuah kegiatan atau interaksi yang saling berkaitan antara aktor dan sistem. Atau secara umum, dapat diartikan sebagai sebuah teknik untuk yang dimanfaatkan untuk pengembangan perangkat lunak (software), guna mengetahui kebutuhan fungsional dari sistem tersebut (Sommerville, 2003).

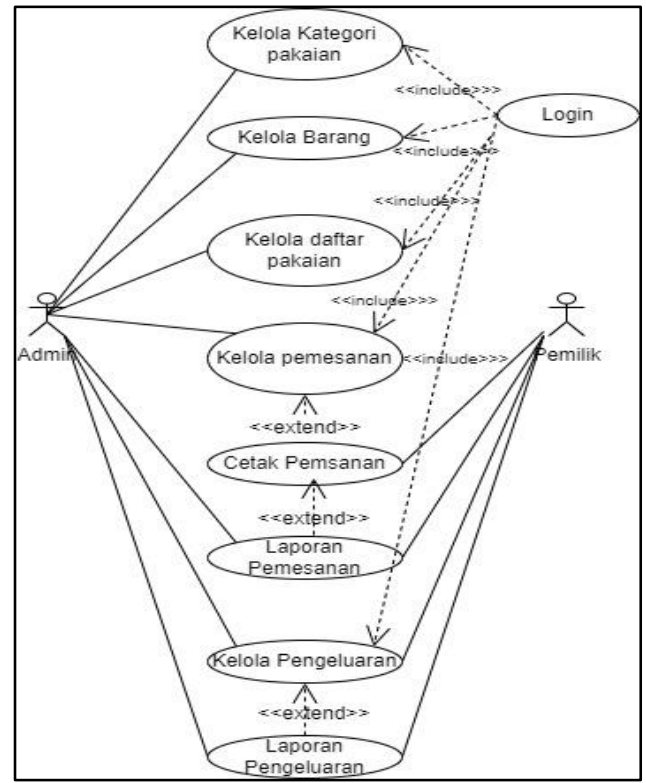

Gambar.2 Usecase Diagram Penjualan 


\section{Perancangan Sistem Penjualan Pakaian Berbasis Web di PT.Quadran Energi Rekayasa Menggunakan Codeigniter3}

Terdapat dua aktor yaitu admin dan pemilik. Admin dapat mengelola kategori pakaian seperti bahan, dan jenis atau tipe pakaian, admin juga mengelola barang yang akan muncul seperti nama barang dan juga kategori, selain itu admin juga dapat mengelola daftar pakaian yang akan dijual. Kemudia admin memproses laporan pemesanan. Lalu admin dan pemilik melakukan proses kelola pengeluaran.

\section{b. Activity diagram}

Dalam bahasa Indonesia diagram aktivitas, yaitu diagram yang dapat memodelkan proses-proses yang terjadi pada sebuah sistem. Runtutan proses dari suatu sistem digambarkan secara vertikal. Activity diagram merupakan pengembangan dari Use Case yang memiliki alur aktivitas.

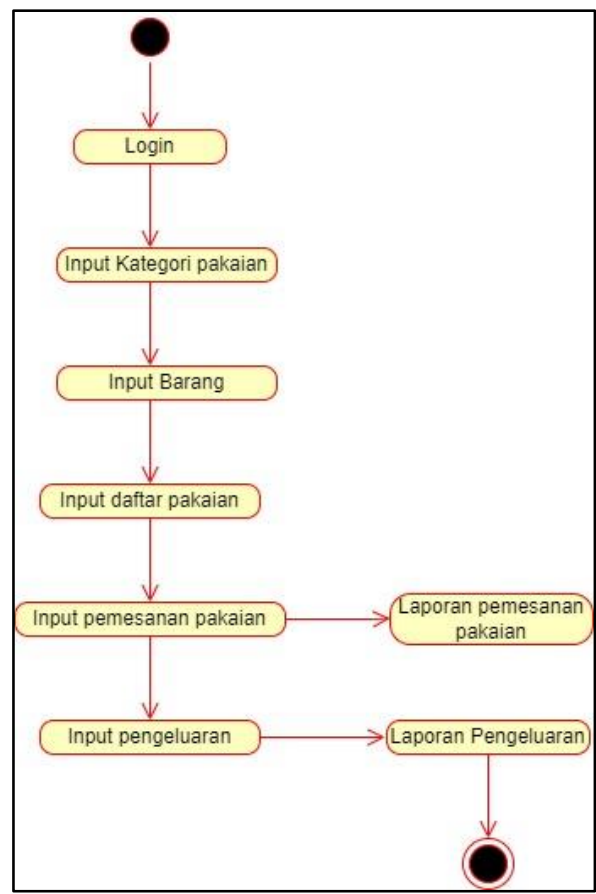

Gambar.3 Diagram Activity

Terdapat delapan aktivitas dari diagram diatas yaitu aktivitas login, aktivitas input kategori pakaian, aktivitas input barang, aktivitas input daftar pakaian, aktivitas input pemesanan pakaian yag dapat langsung mencetak laporan pemesanan, aktivitas input pengeluaran dimana ini bisa mencetak laporan pengeluaran.

\section{c. Diagram class}

Class diagram atau diagram kelas adalah salah satu jenis diagram struktur pada UML yang menggambarkan dengan jelas struktur serta deskripsi class, atribut, metode, dan hubungan dari setiap objek. 


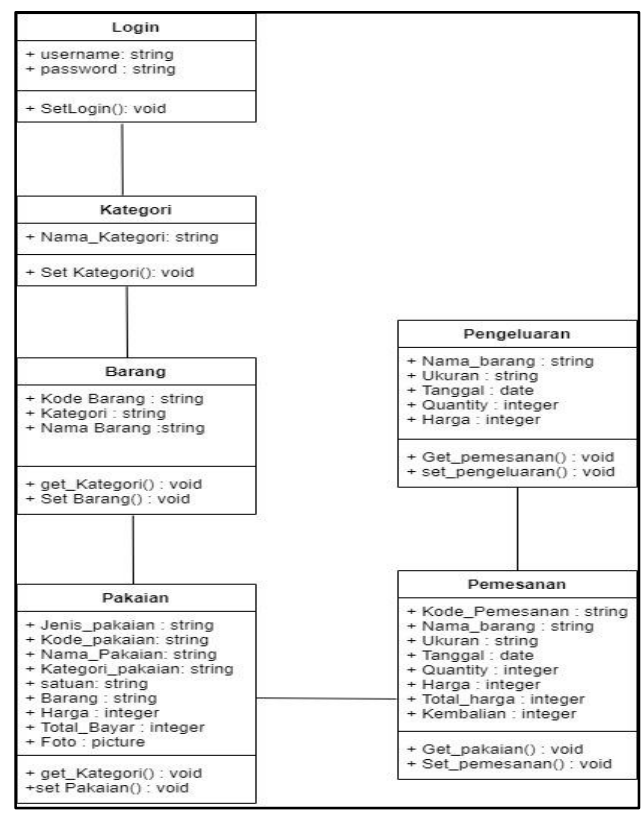

Gambar.4 Class diagram

Terdapat 6 kelas yaitu class login, class kategori, class barang, class pakaian, class pemesanan, dan class pengeluaran. Class login memiliki atribut username dan password, class Kategori memiliki atribut Nama kategori. Class barang memiliki atribut Kode barang, kategori, dan juga.

Nama barang. Class pakaian memiliki atribut jenis pakaian, kode pakaian, nama pakaian, kategori pakaian, satuan, barang, harga, total bayar dan juga harga. Class pemesanan memiliki atribut Kode pemesanan, nama barang, ukuran, tanggal, quantity, total harga dan kembalian. Sedangkan class pengeluaran memliki atribut nama barang, ukuran tanggal, quantity, harga.

\section{d. Statechart}

State diagram adalah diagram yang mendeskripsikan semua Kondisi yang mungkin akan muncul pada suatu objek begitupun dengan event.

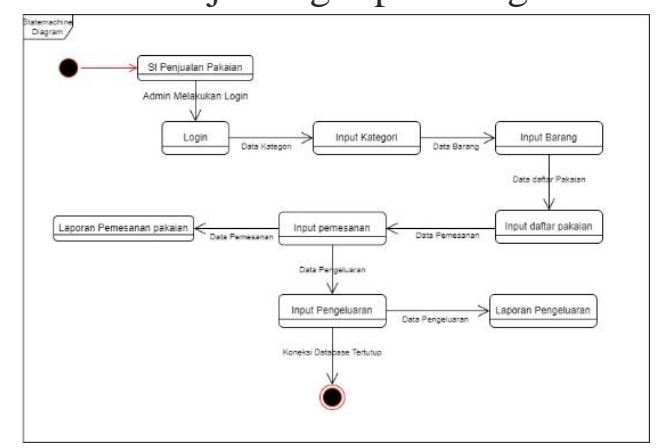

Gambar.5 State Chart Penjualan Pakaian

Terdapat delapan state dari statechart yang diusulkan yaitu dimulai dengan state login, state input kategori, sate input barang, input daftar pakaian, input pemesanan yang dapat langsung menetak laporan pemesanan, dan sate input pengeluaran yang dapat langsung dicetak menjadi laporan pengeluaran. 
Hasil Perancangan Sistem

\section{a. Halaman Login}

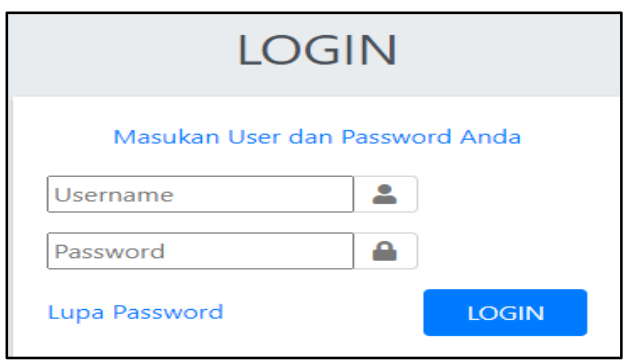

Gambar.6 Halaman Login

Halaman login yaitu username dan password lalu ketika klik button login makan akun akan divalidasi, Jika salah atau lupa akan diarahkan untuk klik Lupa Password

\section{b. Halaman Kategori}

Gambar 7 menujukan form tambah kategori dan Gambar 8 menampilkan halaman kategori

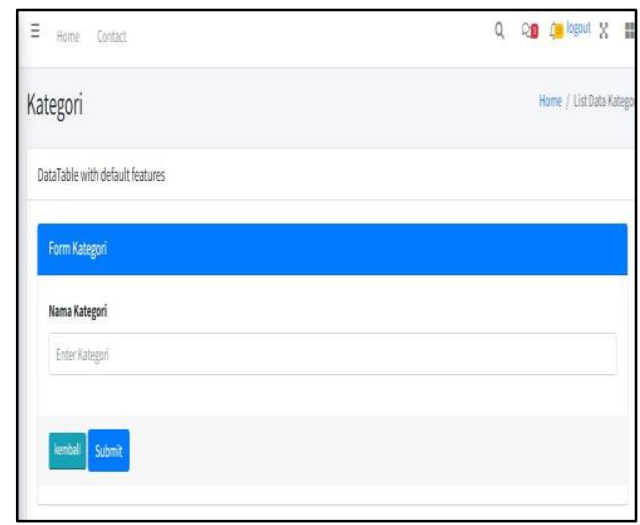

Gambar 7. Form Tambah Kategori

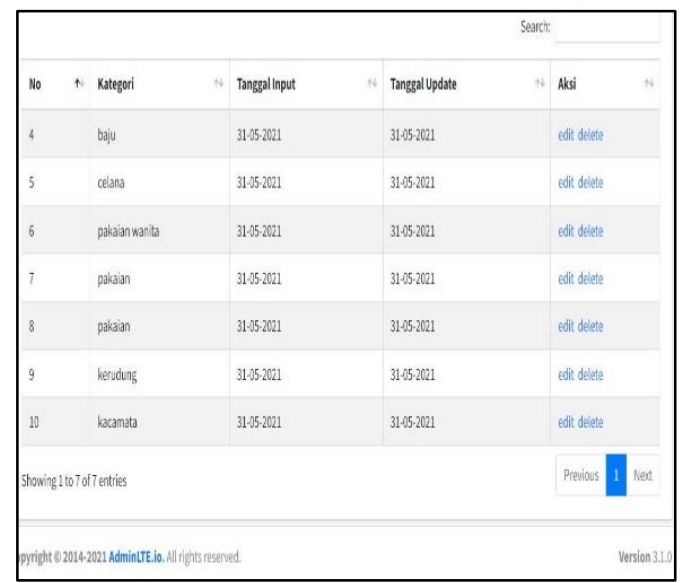

Gambar.8 Halaman Kategori

\section{c. Halaman Tambah Barang}


Resi Alpiana, Widantia Mustika, Rini Tisnawati.

Gambar 9 menunjukan form tambah barang dan gambar no 10 menujukan halaman barang

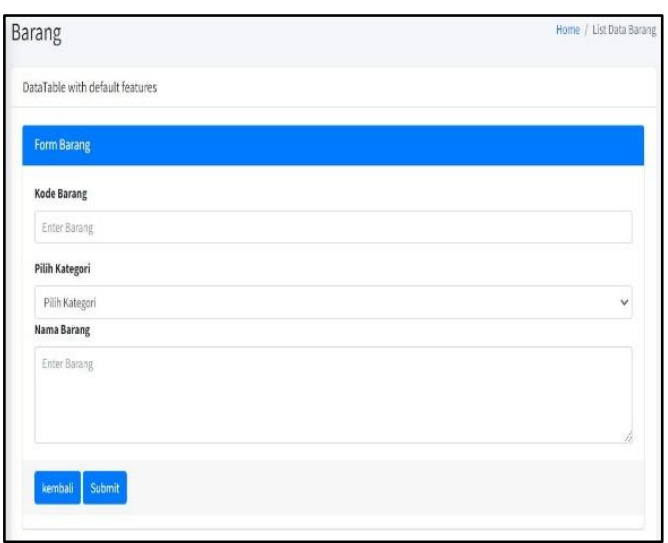

Gambar.9 Form Tambah barang

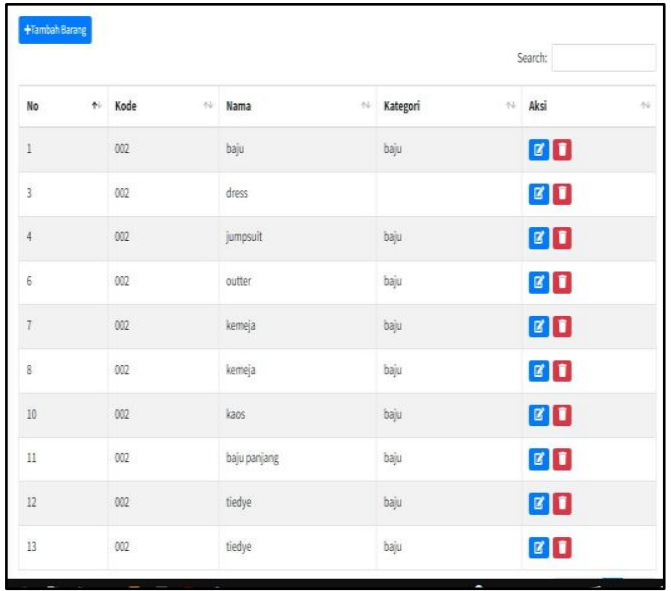

Gambar.10 Halaman Barang

\section{d. Halaman Daftar Pakaian}

Gambar 11 menujukan form untuk mengisi dan menambahkan daftar pakaian yang ada sedangkan gambar no 12 menunjukan halaman daftar pakaian

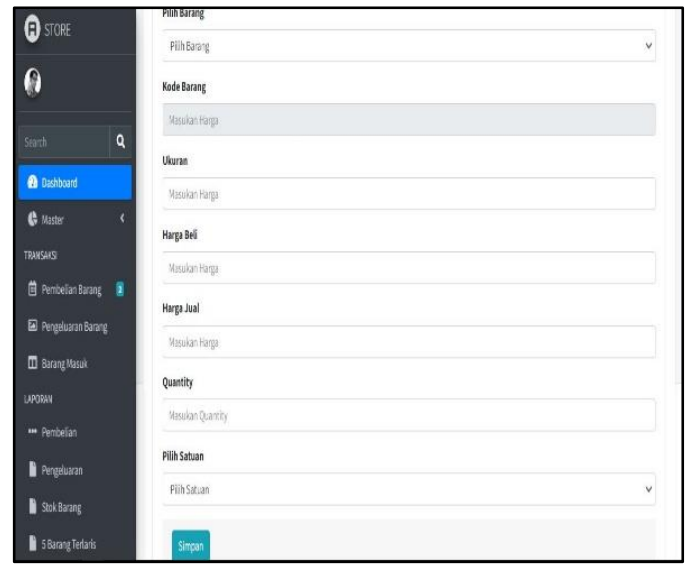

Gambar. 11 form daftar pakaian 
Perancangan Sistem Penjualan Pakaian Berbasis Web di PT.Quadran Energi Rekayasa Menggunakan Codeigniter3

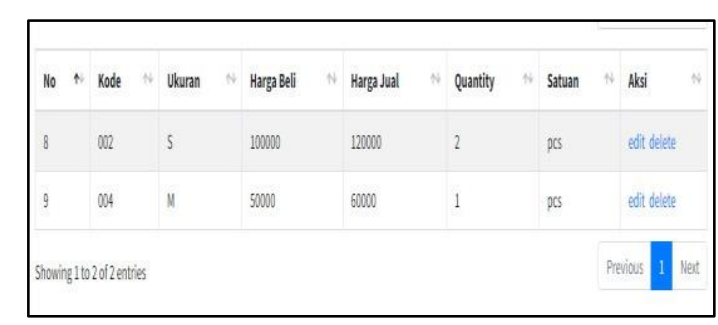

Gambar. 12halaman daftar tambah pakaian

\section{e. Form Pemesanan}

Gambar 13 menujukan form atau halaman untuk memesan pakaian dan gambar 14 menampilkan halaman pemesanan.
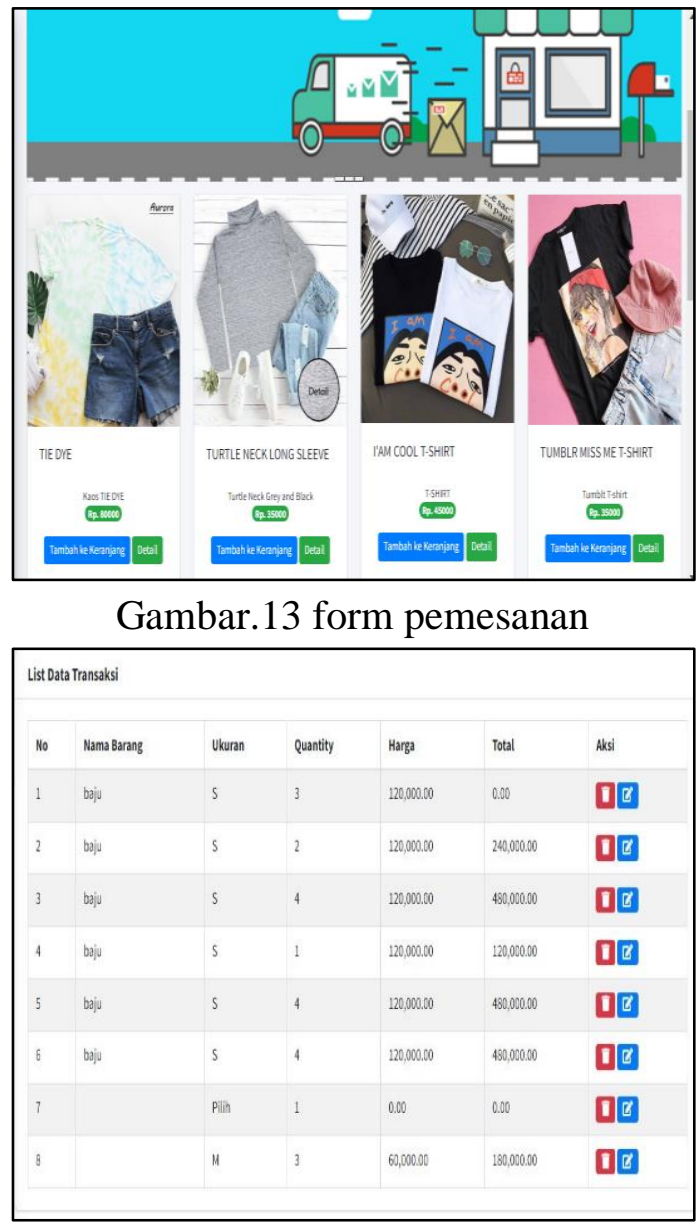

Gambar.14 halaman pemesanan

\section{f. Pengeluaran}

Gambar 14 menampilkan form pengeluaran dan gambar 15 menampilkan halaman pengeluaran. 
Resi Alpiana, Widantia Mustika, Rini Tisnawati.

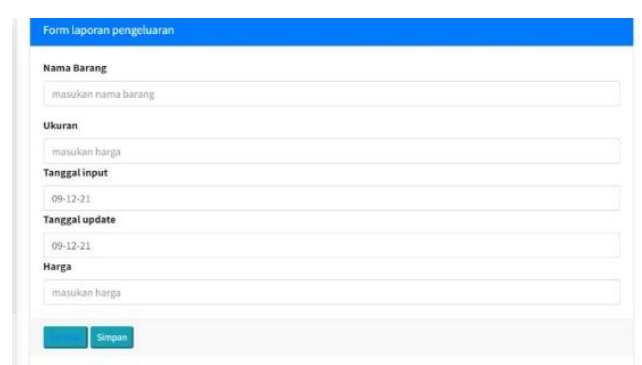

Gambar.14 Form Pengeluaran

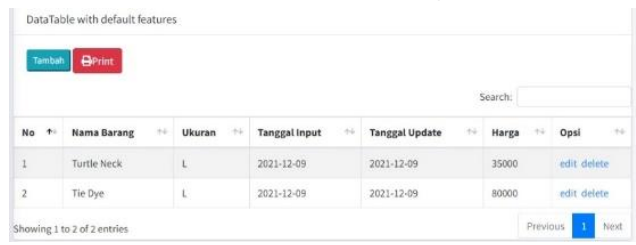

Gambar.15 Halaman Pengeluaran

\section{g. Laporan}

Gambar 15 menampilkan form untuk mengisi laporan dan gamabar 16 menunjukan halaman laporan

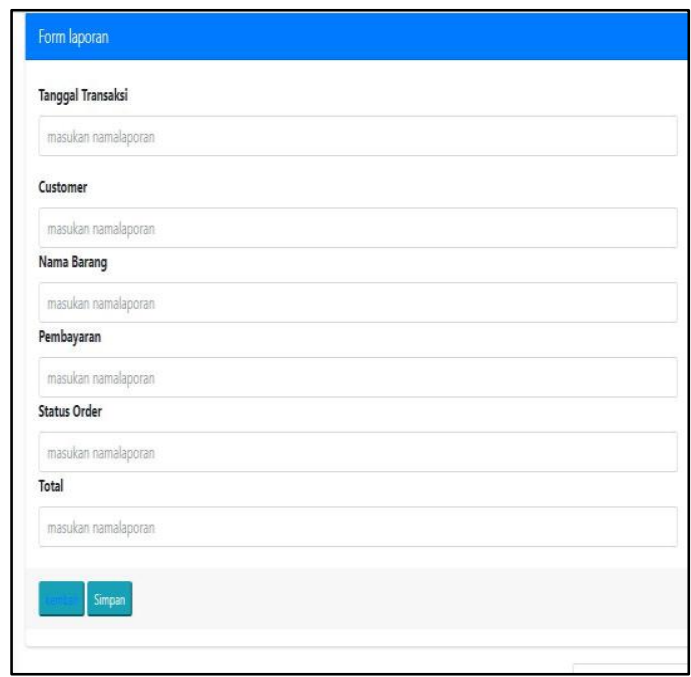

Gambar.15 form Laporan

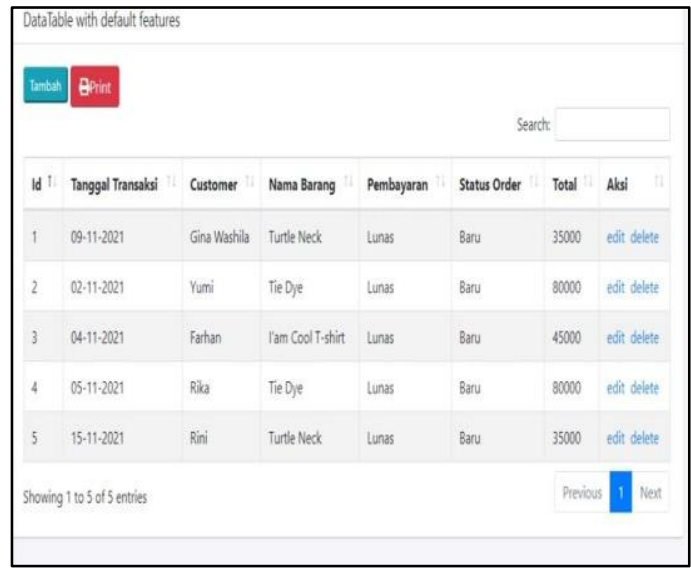

Gambar.16 Halaman Laporan 


\section{Spesifikasi Hardware dan Software}

\section{a. Perangkat Keras (Hardware)}

Dalam merancang Sistem Informasi Penjualan Pakaian ini bebasis web ini dibutuhkan spesifikasi hardware. Berikut spesifikasi yang disarankan.

\begin{tabular}{ll} 
Hardware & \multicolumn{1}{c}{$\begin{array}{c}\text { Contoh } \\
\text { Hardware }\end{array}$} \\
\hline Processor & Intel Celeron \\
\hline RAM & 4GB \\
\hline Hardisk & $\begin{array}{l}250 \text { GB atau lebih } \\
\text { tinggi }\end{array}$ \\
\hline Keyboard & $\begin{array}{l}\text { Kompetible } \\
\text { dengan Ms. }\end{array}$ \\
& Windows \\
\hline Mouse & $\begin{array}{l}\text { Kompetible } \\
\text { dengan Ms. }\end{array}$ \\
& Windows \\
\hline
\end{tabular}

\section{b. Perangkat Lunak (Software)}

Dalam merancang Sistem Informasi Penjualan Pakaian ibebasis web ini dibutuhkan spesifikasi software atau pendukung perangkat lunak untuk membantu membantu merancang sistem. Berikut software yang dibutuhkan :

\begin{tabular}{ll}
\hline Software & Contoh Software \\
\hline $\begin{array}{l}\text { Sistem } \\
\text { Operasi }\end{array}$ & $\begin{array}{l}\text { Ms. Windows 7 } \\
\text { atau lebih tinggi }\end{array}$ \\
\hline Pemograman & PHP \\
\hline Database & My SQL \\
\hline Web Server & XAMPP \\
\hline
\end{tabular}

\section{Kesimpulan}

Setelah melakukan analisis, perancangan, sampai pada tahap pengujian dapat di tarik kesimpulan sebagai berikut: 1 . Sistem Penjualan berbasis web yang yang digunakan masih sistem lama dan lambat dalam hal penginputan pengelolaan data dan laporan.Sehingga dibuatlah sistem yang baru konsumen. 2. Adanya sistem ini semua pengolahan data yang berkaiatan dengan sistem penjualan pakaian terjaga dengan baik. 3. Dengan adanya Pengembangan sistem penjualan pakaian ini diharapkan dapat mengatasi permasalahan yang terjadi 
Resi Alpiana, Widantia Mustika, Rini Tisnawati.

\section{Bibliografi}

Aryani, Dyah. (2020). Rancang Bangun Sistem Penjualan Berbasis WEB (Studi Kasus LORYSIDE STORE YOGYAKARTA). University of Technology Yogyakarta.

Basu. (2008). Mnajemen Penjualan, BPFE. Yogyakarta.

Daqiqil, Ibnu. (2011). Framework Codeigniter: sebuah panduan dan best practice. Pekanbaru: Koder. Web. Id.

Furqon, Ali. (2013). Perancangan Aplikasi Sistem Informasi Penjualan Berbasis Microsoft Access 2007 pada Toko Syafa Collection. Laporan Akhir Politeknik Negeri Sriwijya.

Lestari, Sinta Petri. (2016). Hubungan Komunikasi Pemasaran dan Promosi dengan Keputusan Memilih Jasa Layanan Kesehatan (Studi pada Rumah Sakit Islam Lumajang). Majalah Ilmiah Inspiratif, 2(2).

Nazir, Moh. (2011). Metode Penelitian, Cetakan Ke Tujuh. Bogor: Penerbit Ghalia Indonesia.

Pasaribu, Johni S., \& Taryanto, Ardi. (2018). Implementasi Strategi E-Marketing Berbasis Web (Studi Kasus: Perusahaan Katering Dan Dekorasi). Jurnal E-Komtek (Elektro-Komputer-Teknik), 2(1), 10-22. https://doi.org/10.37339/e-komtek.v2i1.90

Rerung, Rintho Rante. (2018). Pemrograman Web Dasar. Deepublish.

Salahudin, Mohamad, \& Rosa, A. S. (2013). Rekayasa Perangkat Lunak Terstruktur dan Berorientasi Objek. Bandung: Informatika.

Sommerville, Ian. (2003). Software Engineering Rekayasa Perangkat Lunak.

Sugiyono. (2018). Metode Penelitian Kuantitatif, Kualitatif, dan R\&D. Bandung: Alfabeta. https://doi.org/10.33365/joupe.v2i1.950 